\title{
Historia(s) en movimiento: La Primera Guerra Mundial como evento de medios populares en España y México
}

\author{
History(ies) in motion: The First World War \\ as popular media event in Spain and Mexico
}

\author{
Ricarda MUSSER \\ (Instituto Iberoamericano de Berlín) \\ musser@iai.spk-berlin.de \\ ORCID ID: 0000-0001-9715-3641
}

\begin{abstract}
The First World War was a global media RESUMEN: La Primera Guerra Mundial fue un event. Several magazines with different aims and acontencimiento mediático mundial. Diversas takes reported about the occurencies in texts and revistas con distintos objetivos y posturas images. This also was the case in Spain and Mexico. publicaron al respecto desde el texto y los gráficos. The information was disseminated both in an Este es el caso de España y México, en donde la informative context and with the intention to evoke información se transmitía en un contexto más emotions in accordance with the publications focus. informativo o más destinado a despertar emociones dependiendo de las intensiones de la publicación.
\end{abstract}

Keywords: History, First World War, Mexico, PAlabras-Clave: Historia, Primera Guerra Spain, illustrated magazines

Mundial, México, España, revistas ilustradas

\section{LA GUERRA EN LOS MEDIOS}

La Primera Guerra Mundial fue, entre otras cosas, también un acontecimiento mediático. Diarios y revistas informaban extensamente sobre lo que ocurría en Europa y numerosas publicaciones periódicas cubrían exclusivamente la actualidad bélica. Esto puede constatarse no solo en los países directamente implicados en la guerra, sino también en países neutrales como México y España.

En España, en la Gaceta de Madrid del 7 de agosto de 1914, se podía leer:

Declarada, por desgracia, la Guerra en Alemania, de un lado, y Rusia, Francia y el Reino Unido de Gran Bretaña é Irlanda, sucesivamente, de otro, y existiendo el estado de Guerra en Austria Hungría y Bélgica, el gobierno de S.M. se cree en el deber de ordenar la más estricta neutralidad a los súbditos españoles (Gaceta, 1914: 306).

Y, sin embargo, en España se disputó una guerra; una guerra que los partidarios de cada bando libraron en las páginas de los diarios. En las revistas Iberia y España. Semanario de la vida nacional, el escritor Ramón Pérez de Ayala publicó el «Manifiesto de adhesión a las naciones aliadas», firmado por intelectuales como José Ortega y Gasset, Fernando de los Ríos, Valle Inclán, Miguel de Unamuno y Gregorio Marañón. Al mismo tiempo, se fundaron revistas como Germania, que defendían la entrada en la guerra a favor de Alemania. Ambas convicciones encontraban eco en publicaciones como $\mathrm{El}$ Imparcial. 
En México, un país geográficamente alejado de la guerra, la cobertura de los medios también permitía estar muy bien informado en todo momento. A las noticias propiamente dichas se unían numerosos editoriales y artículos de opinión. Así, en 1915 la Revista de Revistas inició una encuesta entre los intelectuales mexicanos acerca de la Guerra Europea. También surgieron publicaciones periódicas específicas que informaban exclusivamente sobre lo que pasaba en Europa, como La guerra europea: crónica ilustrada (1914-1919), Boletín de la guerra por la verdad (1914-1919), El heraldo europeo: semanario de la guerra europea (1915) y La Actualidad. Revista de los Aliados (1915-1917), todas ellas con una actitud en mayor o menor medida antigermana. En la revista La Actualidad del 1 de diciembre de 1915 Salvador E. Gutiérrez y otros planteaban la siguiente pregunta: ¿Por qué existen algunos «germanófilos» en México? Gutiérrez ofrecía las siguientes respuestas:

Encuentro dos explicaciones de este hecho: es la primera la ignorancia que generalmente existe, por parte de las personas que discuten sobre el actual conflicto, desde el punto proalemán, respecto de las verdaderas causas de la guerra, de los verdaderos ideales por cuyo triunfo combaten a muerte las naciones conflagradas. La segunda explicación es ésta: existe en todos los pueblos, bajo diversas formas, o más bien dicho, con objetos diversos, un sentimiento de admiración hacia todo lo que significa fuerza triunfadora (Gutiérrez, 1915: 411).

A continuación exponía los argumentos por los que los mexicanos «debemos pensar y sentir a favor de los aliados» (Gutiérrez, 1915: 411). Un extenso artículo de José Mesa Gutiérrez, profesor de Psiquiatría en la Escuela Nacional de Altos Estudios, indaga en «El complejo conquistador alemán. Sus expresiones indirectas» (Mesa Gutiérrez, 1916: 765). Los textos se acompañaban de las pertinentes caricaturas. La edición del 30 de diciembre de 1916 muestra al káiser alemán a punto de ahogarse mientras con una mano extiende hacia lo alto una paloma de la paz. La imagen va acompañada de la leyenda: «Estoy completamente dispuesto a hacer la paz!» (Actualidad, 1916: 828).

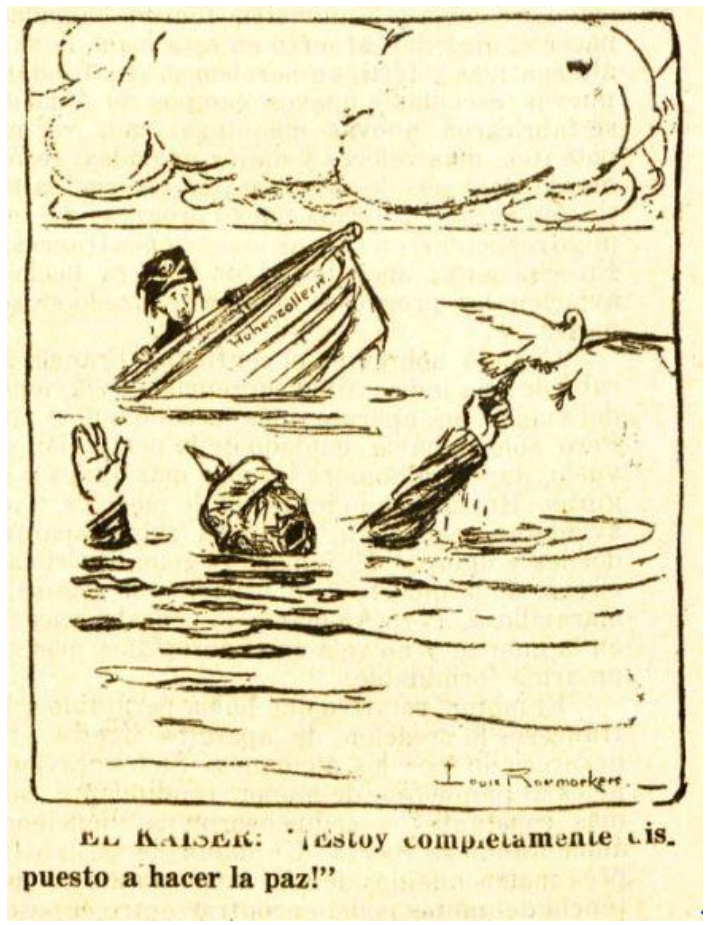


En general, los Aliados eran presentados de forma muy positiva. «Francia defiende el mundo latino», se titulaba el artículo del escritor español Vicente Blasco Ibáñez para la revista Actualidad. No era raro, por cierto, encontrar textos de autores españoles en los medios mexicanos. Otro ejemplo es la parodia «La nueva canción del pirata» del poeta, humorista y periodista español Luis de Tapia, publicada también en Actualidad. El poema original, de José de Espronceda, uno de los máximos representantes de la poesía romántica española, fue publicado por primera vez, con el título de «Canción del pirata», en 1835 en la revista El Artista (1835: 43-44). Comparamos la primera estrofa de ambas versiones:

\author{
Canción del pirata \\ (José de Espronceda) \\ Con diez cañones por banda, \\ viento en popa, a toda vela, \\ no corta el mar, sino vuela \\ un velero bergantín. \\ Bajel pirata que llaman, \\ por su bravura, El Temido, \\ en todo mar conocido \\ del uno al otro confín.
}

\author{
La nueva canción del pirata \\ (Luis de Tapia) \\ Con dos torpedos por banda, \\ y corriendo tras la presa, \\ no corta el mar, lo atraviesa, \\ un submarino alemán... \\ Bajel pirata que llaman, \\ en su país el «U 12», \\ $\mathrm{y}$ de quien nadie conoce \\ «situación», ni capitán..
}

Esta parodia introduce muy bien el tema que a continuación queremos analizar, a saber, cómo se expuso la guerra en los medios populares de España y México en forma de fotografía, caricatura y texto. Como ejemplos de esos medios populares tomaremos revistas ilustradas cuyas características comunes consisten en que se dirigen a un público general y cubren un amplio abanico de temas, desde la moda y la belleza, pasando por la literatura y el teatro, hasta los avances de la medicina y la industria. Otro rasgo distintivo es la estrecha relación entre imagen y texto, y la amplia proporción de espacio dedicado a los anuncios publicitarios.

\section{ESPAÑA: MUNDO GRÁFICO}

En el caso español analizaremos la revista Mundo Gráfico, publicada en Madrid entre 1911 y 1938 . Concebida como la publicación más popular y de más bajo precio de la empresa Prensa Gráfica, el porcentaje de ilustraciones llegaba al 90\%. Mundo Gráfico se convirtió en una de las revistas españolas de mayor tirada de la época, con un volumen de ventas de entre 80.000 y 130.000 ejemplares por semana. Los temas españoles eran prioritarios. Se informaba regularmente de las funciones de teatro y zarzuela, y se publicaba y reseñaba nueva literatura. La actualidad taurina y el teatro ocupaban una amplia parte de las ilustraciones, así como las noticias sensacionalistas, por ejemplo reportajes ilustrados sobre asesinatos especialmente espeluznantes o conmovedoras historias familiares. Las noticias internacionales, fuera de las referidas a la Primera Guerra Mundial, atañían sobre todo a las naciones latinoamericanas. Solo en casos aislados se publicaban noticias procedentes de los países beligerantes que no estuviesen directa o indirectamente relacionadas con la guerra.

En definitiva, la Primera Guerra Mundial ocupaba bastante espacio en la revista. La información al respecto llegaba a la editorial a través del corresponsal en Londres, Manuel Barroso, mientras que el material fotográfico venía de las agencias Hugelmann, Central News, Chusseay Flaviens y Underwood. 
Nos ocuparemos en primer lugar de las fotografías de Mundo Gráfico. La publicación muestra sin diferenciación fotos de la guerra de todas las naciones beligerantes en el más amplio abanico temático. Se reproducen armas y maquinaria militar, a menudo por ejemplo submarinos alemanes, pero también, cañones alemanes apresados por los franceses (véase Mundo Gráfico, 326, 23 de enero de 1918). También se dedica bastante espacio a fotografías de las personas más influyentes en la guerra, con retratos de los monarcas de los países beligerantes, como los káiseres alemán y austríaco, o la familia de los zares rusos, así como fotografías de comandantes y generales. Un interesante ejemplo es la contraposición fotográfica de los directores alemanes y los directores aliados de la gran batalla (Mundo Gráfico, 342, 15 de mayo de 1918), en referencia a la batalla de los emperadores que tuvo lugar entre marzo y abril de 1918, separada por la reproducción y breve exposición del funcionamiento de un nuevo cañón electromagnético. Hoy, esta distribución recuerda a la disposición de los personajes de un videojuego (inclusive la presentación del arma que tal vez se pueda ganar en el desarrollo de la partida) o a la presentación de los protagonistas de un programa de telerrealidad o de ciencia ficción, como la adaptación cinematográfica de la trilogía distópica The hunger games (Los juegos del hambre) de Suzanne Collins.

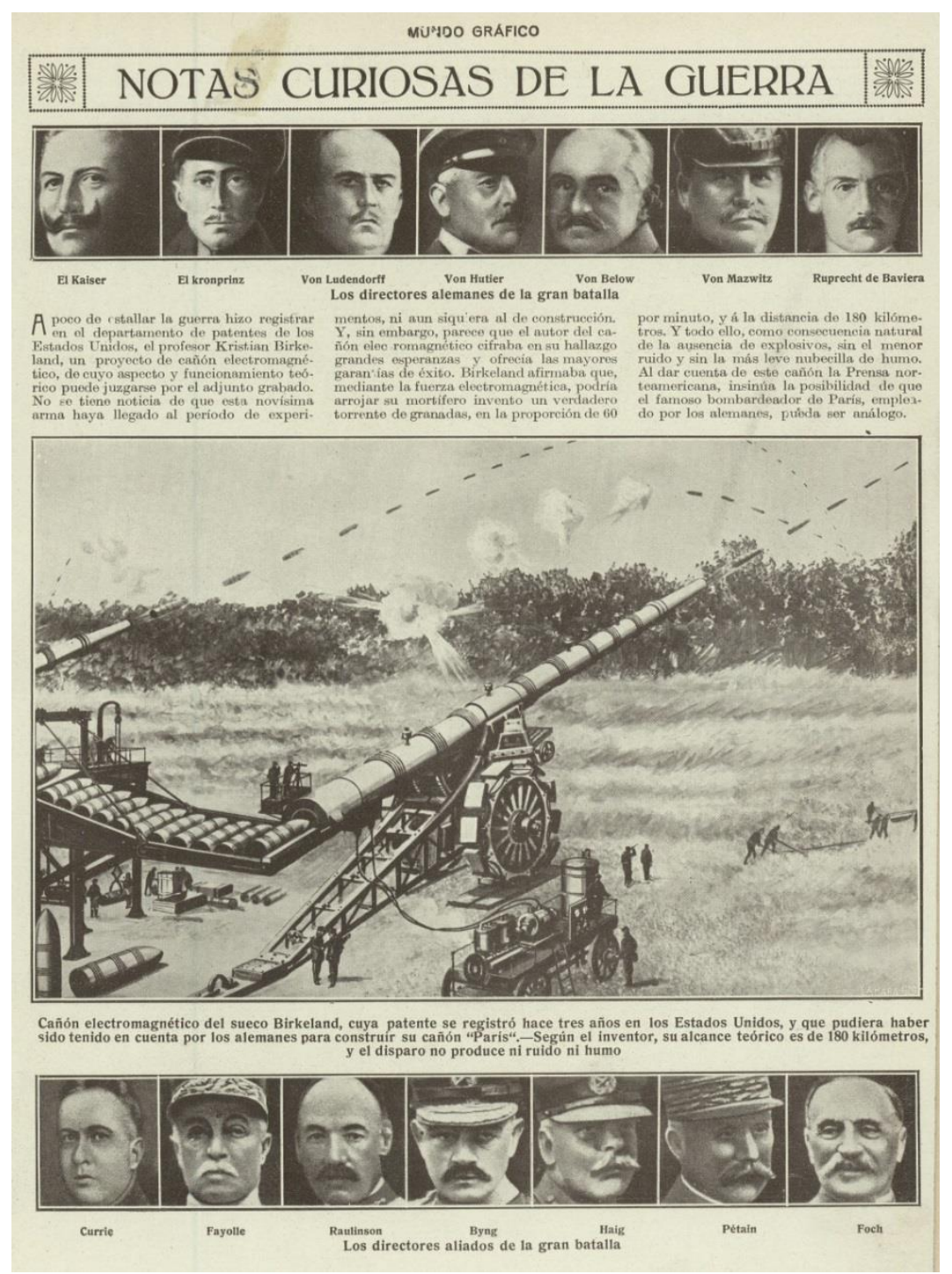


Otro apartado lo ocupan las fotografías de los horrores de la guerra, por ejemplo los muertos o heridos, en los campos de batalla (véase Mundo Gráfico, 344, 29 de mayo de 1918). A la vez, también hay espacio para mostrar las consecuencias de la guerra para la población civil (véase Mundo Gráfico, 167, 6 de enero de 1915). Hay ciudades y pueblos destrozados, niños que quedan huérfanos, y mujeres que enviudan y que a partir de las ruinas deben intentar reconstruir sus vidas. Bajo el título «Notas curiosas de la guerra» se agrupan numerosas fotografías que recogen muy diversas observaciones y momentos relacionados con la guerra, como por ejemplo el reloj parado en el Marne (véase Mundo Gráfico, 324, 9 de enero de 1918).

Un aspecto interesante al que también se dedican algunas fotografías es el nuevo papel de la mujer en la guerra. Al respecto encontramos, por un lado, fotografías de mujeres que trabajan en la industria de armamento y de esta manera participan en la guerra en su patria (véase Mundo Gráfico, 298, 11 de julio de 1917), pero también, por otro lado, fotografías que documentan cómo las mujeres, obligadas por la necesidad en tiempos de guerra, prueban oficios que hasta entonces solían desempeñar los hombres, en este caso bajo el título «Mujeres neoyorquinas substituyendo á los hombres en diversos oficios, por causa de la guerra» (Mundo Gráfico, 326, 23 de enero de 1918).

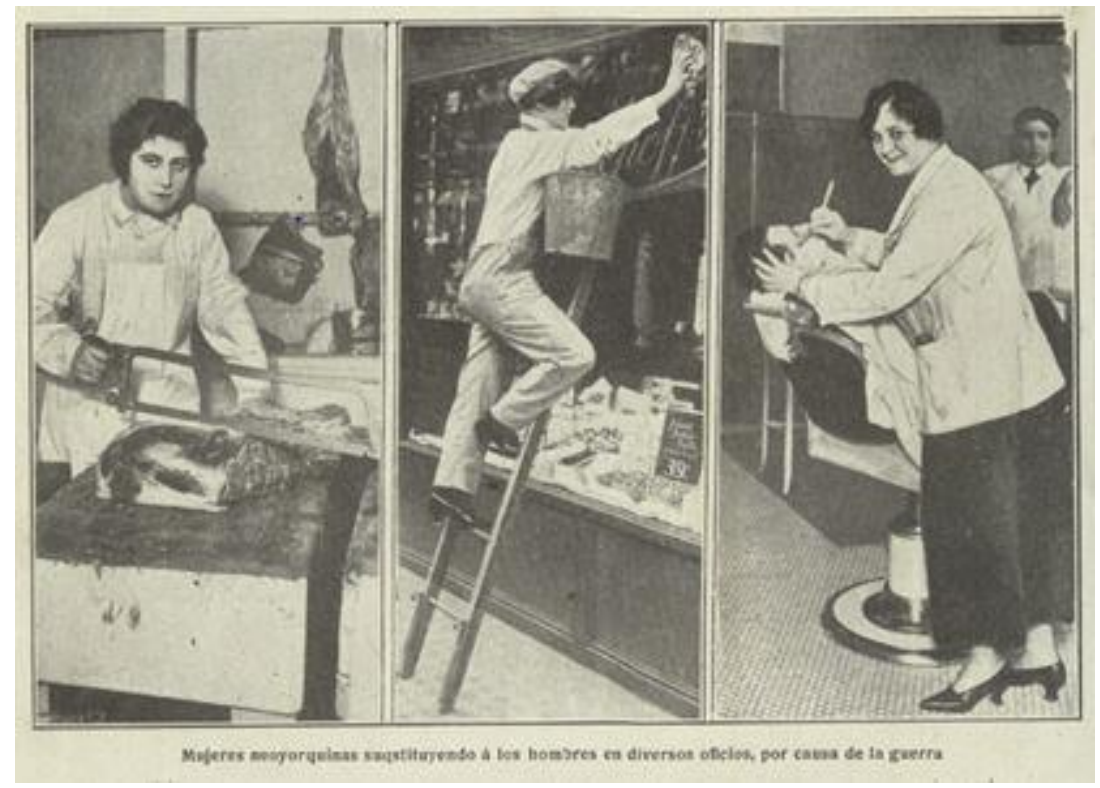

Lo interesante aquí es que tras el fin del conflicto este tema se retomará para mostrar a mujeres que siguen haciendo trabajos considerados «de hombre» aun cuando estos ya han vuelto de la guerra. Por otro lado, encontramos fotografías que recuerdan a películas de Hollywood o a espectáculos de revista, como el beso bajo el título «El amor y la guerra» (véase Mundo Gráfico, 309, 26 de septiembre de 1917) o la instantánea de las «Damas de la colonia francesa en Londres» (véase Mundo Gráfico, 249, 2 de agosto de1916).

Los cambios sociales en los países en guerra, como la Revolución de Octubre de 1917 en Rusia o la de Noviembre de 1918 en Alemania, se transmitían de forma gráfica mediante la presentación de los correspondientes monarcas, con la foto del zar y la información sobre su ejecución (véase Mundo Gafico, 352, 24 de julio de 1918), y lo mismo con la abdicación del emperador alemán (véase Mundo Gráfico, 368, 13 de 
noviembre de 1918). Finalmente, el final de la guerra se documenta fotográficamente con instantáneas de las masas festejando (véase Mundo Gráfico, 371, 4 de diciembre de 1918).

Por norma general, las imágenes iban acompañadas solo de textos muy breves, por lo que la idoneidad de la revista como medio de información sobre la guerra se veía limitada. La publicación intentaba más bien apelar a los sentimientos de los lectores y lectoras, y despertar emociones.

Muy rara vez encontramos otros tipos de ilustraciones en Mundo Gráfico. A primera vista resulta sorprendente que apenas haya pocas caricaturas relacionadas con el conflicto bélico, sobre todo teniendo en cuenta que la caricatura en sí es un elemento recurrente en la revista. Sin embargo, esta se empleaba normalmente en relación con el ámbito del arte, el teatro y la literatura, por lo que quedaba circunscrita a las noticias nacionales y culturales. Por otro lado, Mundo Gráfico no era una revista política en la que la caricatura política o de crítica social ocupase un lugar natural. La revista publica en una sola ocasión un mapa en color de la guerra (véase Mundo Gráfico, 369, 20 de noviembre de 1918). Y también en una sola ocasión un motivo militar ocupa el diseño de portada, normalmente dedicado a fotografías o deseños de mujeres (véase Mundo Gráfico, 168, 13 de enero de 1915).

En cuanto a textos que se puedan adscribir a tradiciones populares, en las Páginas Literarias de Mundo Gráfico se encuentran algunos, aunque no muchos, poemas sobre la guerra y la paz. Con motivo de la Pascua, el 27 de marzo de 1918 se publica una «Oración de Paz» de Francisco de Iracheta en la que fervorosamente se pide a Dios el fin de la sangrienta Guerra (Iracheta, 1918: s. p.). Rezar por cuestiones que están en armonía con los ideales cristianos, como la paz, era parte integrante de la devoción católica. «iHaya Paz!» de Manuel Soriano retoma en la cuarta estrofa el tema de la oración, sin que se aprecien, en principio, preferencias o simpatías por alguna de las partes. Alemanes y franceses son recordados por igual (Soriano, 1916: s. p.).

El poema «Carta de la Guerra» de Félix Méndez Martínez no estaba inspirado en la Primera Guerra Mundial. Su autor había muerto ya a finales de 1913. Se trata, de nuevo, de una parodia, lo que podemos enlazar con el poema del principio, que aborda el sinsentido de la guerra, o mejor aún, la vacuidad de los conflictos bélicos (Méndez Martínez, 1918: s. p.).

\section{MÉXICO: EL UNIVERSAL ILUSTRADO}

En México, a partir del 11 de mayo de 1917 se comenzó a publicar El Universal Ilustrado. Semanario artístico popular. 1917 fue también el año en que el neutral México se vio asociado internacionalmente a la guerra en el contexto del llamado telegrama Zimmermann, un texto cifrado que el ministro de Asuntos Exteriores del Imperio alemán, Arthur Zimmermann, envió en enero de 1917, a través de la Embajada alemana en Washington D.C., al embajador alemán en México. El mensaje proponía una alianza entre Alemania y México para el caso de que Estados Unidos renunciase a su neutralidad. El telegrama fue interceptado y descifrado por la Inteligencia Naval Británica, y transmitido a los Estados Unidos más de un mes después (véase Schwarze, 2013 y Boghardt, 2012).

El Universal Ilustrado era el suplemento cultural del periódico El Universal y se convirtió en una de las revistas más populares de México. Cada número costaba 40 centavos y constaba de 20 páginas. En su primera edición, el redactor jefe, Carlos González Peña, describía la orientación de la revista en cuanto a sus contenidos: 
El Universal Ilustrado no es un periódico de sensacionalismo brutal ni de desenfrenado noticierismo. Ha procurado colocarse en el justo medio: informar, pero también enseñar. [...] Queremos que El Universal ilustrado sea la revista de todos, el amigo de los hogares; el semanario preferido de quienes gustan de las publicaciones que, amén de rendir pleito homenage a lo actual, lleven en sus páginas mucho de espiritualidad discreta, de amena cultura (González Peña, 1917: s. p.).

Volvamos a las fotografías. En El Universal Ilustrado se encuentran muy pocas fotografías de la guerra, y nunca en gran formato. En cuanto a su temática, muestran o bien ruinas, o bien las tropas de los países en guerra (véase El Universal ilustrado, 33, 21 de diciembre de 1917), así como a los generales al mando (véase El Universal ilustrado, 10, 13 de julio de 1917). Vuelven a ser tema las mujeres, esta vez las francesas, que han asumido los trabajos que en tiempos de paz hacían los hombres (véase El Universal Ilustrado, 31, 7 de diciembre de 1917). Esta revista, sin embargo, no publica fotografías dirigidas en primera instancia a conmover a los lectores.

En cambio, encontramos en El Universal Ilustrado muchas más ilustraciones no fotográficas. En primer lugar podemos nombrar las reproducciones de pinturas. Para ilustrar una crítica literaria de la obra La Matanza de los Inocentes del escritor belga Maurice Maeterlinck del año 1886 se usa a doble página una obra del pintor mexicano Saturnino Herrán, que en su representación de la escena incorpora a militares alemanes matando a niños. El texto del que bebe la obra se encuentra en el Nuevo Testamento, en Mateo 2, 16-18, y narra la matanza de los inocentes en Belén, ordenada por el rey Herodes. La invasión de Bélgica de las tropas alemanas estuvo acompañada de sangrientas masacres contra la población civil (véase El Universal ilustrado, 1, 11 de mayo de 1917).

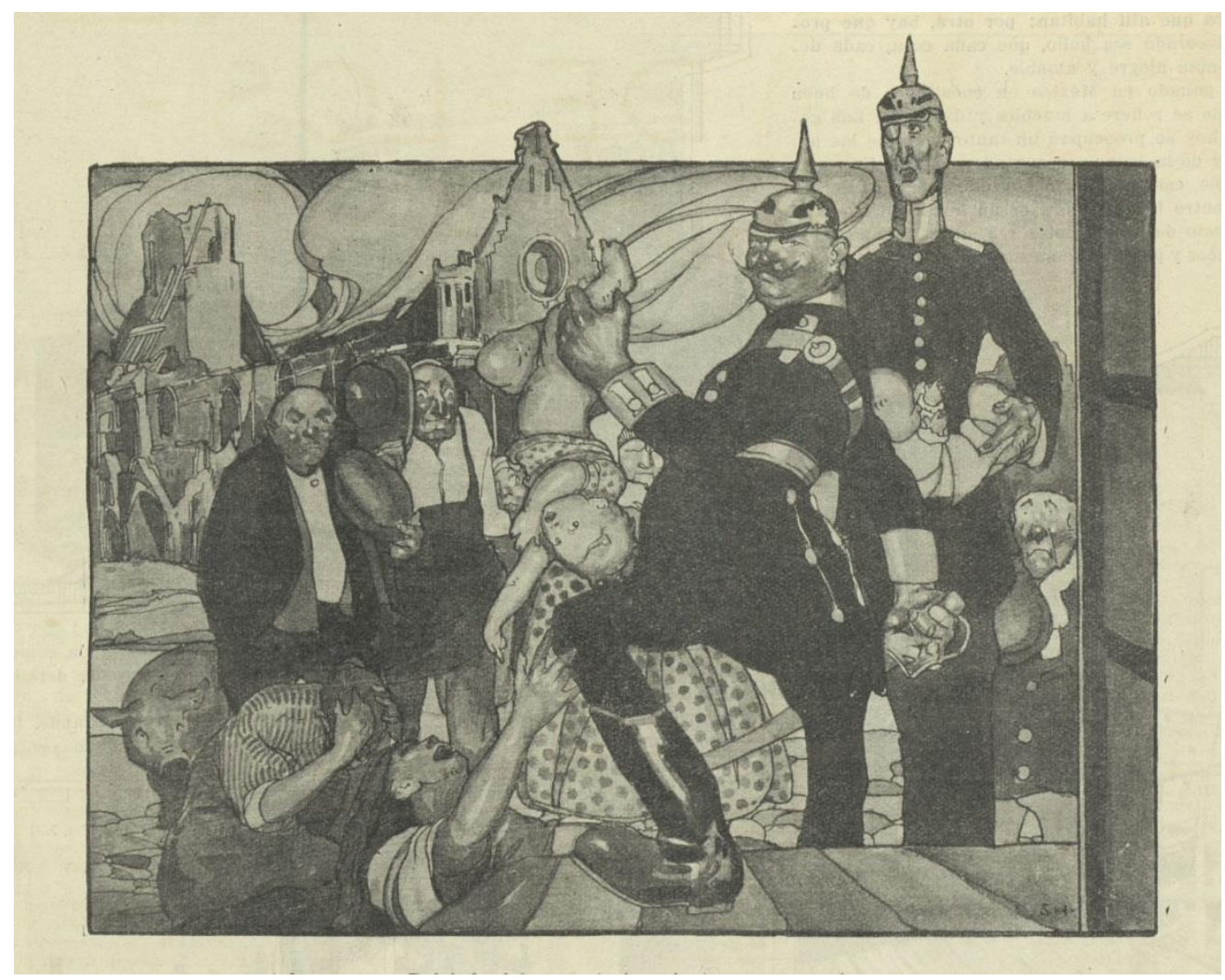


En 1918 la revista publica numerosas caricaturas sobre la Primera Guerra Mundial. En los casos en que contienen una nota sobre el origen, se trata de caricaturas que llegaron por el último barco, publicadas ya en las revistas parisinas Le Journal y Le Matin. Esto significa, claro, que son caricaturas antigermánicas protagonizadas por el káiser, casi siempre el alemán, pero en algunos casos también el austríaco. Marca el comienzo una caricatura (El Universal ilustrado, 39, 1 de febrero de 1918) que muestra al emperador alemán junto al rey belga.

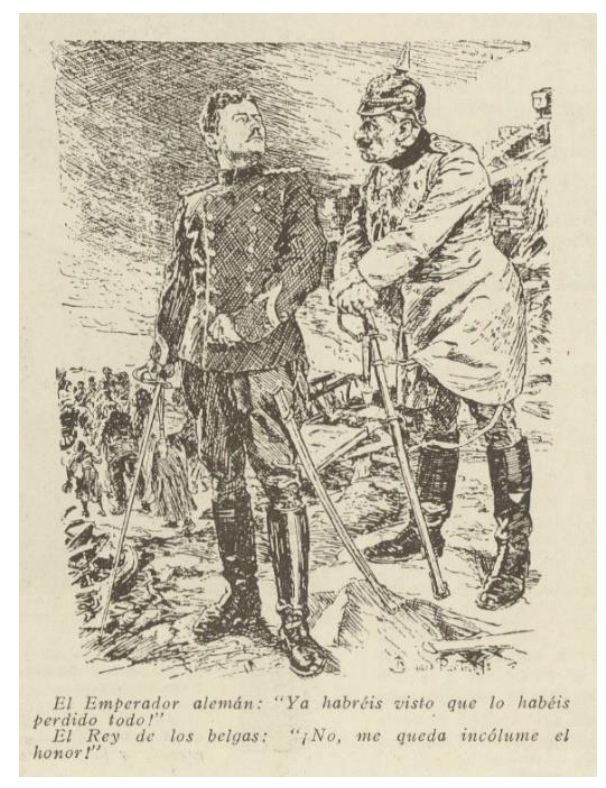

Más adelante las caricaturas en pequeño formato ocuparán media página y se referirán en su mayor parte a acontecimientos actuales, como es el caso de la caricatura «Las pérdidas alemanas», con la leyenda «El Húsar de la Muerte ante Amiens-Batiré el record de Verdun» (El Universal ilustrado, 56, 31 de mayo de 1918). La batalla de Amiens tuvo lugar en agosto de 1918 y terminó con la victoria de los Aliados. Verdún se refiere a la batalla de Verdún, que comenzó el 21 de febrero de 1916. En ella las pérdidas alemanas ascendieron a 337.000 soldados, de ellos 150.000 caídos.

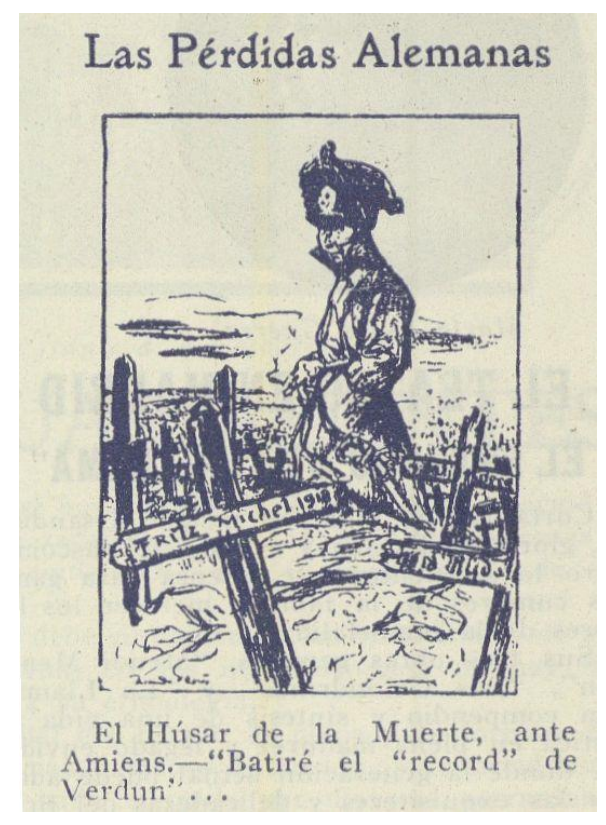


No encontramos en El Universal Ilustrado ejemplos de otras representaciones gráficas, como mapas.

En la revista hay pocos textos sobre la Primera Guerra Mundial. Ocupan un espacio relativamente amplio extractos del libro Mis cuatro años en Alemania (My 4 years in Germany) del ex embajador estadounidense en Alemania James Watson Gerard, que ocupó ese cargo desde 1913 hasta 1917, cuando regresó a Estados Unidos con motivo de la entrada de su país en la guerra. Además del libro mencionado, escribió otro titulado Face to face with Kaiserism del año de 1918. Los fragmentos publicados en El Universal Ilustrado tratan sobre todo de lo que podemos adscribir a la llamada psicología de los pueblos, con una pregunta clave: ¿cómo son realmente los alemanes. Así, los lectores leen sobre un «ciego instinto de guerra y conquista» cuyo origen se remonta a la época romana, y sobre cómo «la autocracia alemana nació del miedo» (Watson Gerard, 1918a: s. p.). Por deseo de los lectores, en un número posterior se publica más información de la pluma del ex embajador sobre Alemania, referida sobre todo a la vida cotidiana más allá de la guerra (Watson Gerard, 1918b: s. p.).

En media página aparece una exposición del ensayista y escritor Leopoldo Lugones, con el título «La Nueva civilización». El texto comienza con el surgimiento de la Liga de las naciones, fundada con idealismo americano para hacer frente a la cultura alemana (Lugones, 1918: s. p.). Los fragmentos de una entrevista con Manuel Romero de Terrero tratan no tanto de la guerra en sí, como de la pregunta de si los españoles son «germanófilos». El entrevistado responde afirmativamente y especifica que considera germanófilos a alrededor del 70\% de los españoles (Bona-Fide, 1917: s. p.).

En el número del 13 de julio de 1917 se publicó un relato titulado «Los cuentos de 1914: La Marsellesa del Kronprinz», junto a una narración de Alphonse Daudet referida a la guerra franco-prusiana de 1870/71. Ambos relatos van acompañados de ilustraciones de Saturnino Herrán. El autor de la narración firma como Ch. A. Oficial enfermero. La historia está ambientada en un municipio francés tomado en repetidas ocasiones por ejércitos alemanes y franceses. El tono es profrancés. Al ejército del príncipe heredero se lo denomina «los bárbaros» (A. 1917: s. p.).

Finalmente, encontramos en las páginas de la revista un poema del escritor gallego Ramón Goy de Silva titulado «La guerra submarina. Poesía moderna de actualidad y utópica» (Goy de Silva, 1917: s. p.). El poema se compone, como ya sugiere el subtítulo, de dos partes, hoy y mañana. El título se refiere a una innovación técnica en la guerra, a saber, la guerra submarina. El 22 de febrero de 1915 el gobierno del Reich había decretado ya la guerra submarina sin restricciones contra los buques mercantes tanto de los países en guerra como de los países neutrales. El texto se refiere además a los llamados dreadnoughts, un nuevo tipo de barco de guerra que entró en servicio en 1906. La de Jutlandia en 1916 fue la única batalla de la Primera Guerra Mundial en la que se enfrentaron estos acorazados, pues en vista de las elevadas pérdidas se cuestionó la idea misma de librar batallas entre dreadnoughts. Para el mañana, Goy de Silva establece un vínculo con el escritor británico de ciencia ficción Herbert George Wells, cuyas novelas más conocidas, La máquina del tiempo (The time machine, 1895) y La guerra de los mundos (The war of the worlds, 1898) ya se habían publicado a finales del siglo XIX. En definitiva, la guerra submarina y sus posibles desarrollos resultan tan increíblemente nuevos y extraños que Goy de Silva los sitúa en las proximidades de la ciencia ficción. 


\section{CONCLUSIONES}

Como mencionamos al comienzo, la Primera Guerra Mundial fue un acontecimiento mediático mundial. Las revistas ilustradas estaban entre los medios apropiados para informar sobre su transcurso, como hemos podido mostrar con dos ejemplos. Dependiendo de las pretensiones de cada publicación, la información se transmitía en un contexto más informativo o más destinado a despertar emociones. Así, se daban grandes variaciones en la proporción de elementos gráficos y textuales. La postura general de ambos países, España y México, hacia la guerra, se refleja también en las respectivas revistas ilustradas.

Resulta interesante observar los estrechos lazos entre medios internacionales durante la Gran Guerra. Mundo Gráfico tomaba fotografías de varias agencias extranjeras y El Universal Ilustrado publicaba caricaturas francesas y poemas españoles, lo que podemos interpretar como un testimonio del avance de la globalización de los medios ya a principios del siglo XX.

Además, en los textos sobre la Primera Guerra Mundial se hace referencia a producciones literarias de la preguerra, como las novelas de Wells, una narración de Alphonse Daudet o un poema del Romanticismo español. Al mismo tiempo se imprimen fragmentos de obras de muy reciente publicación, como el libro del ex embajador estadounidense en Alemania. Podríamos por ello suponer una cierta pretensión didática en las respectivas redacciones en cuanto a educación literaria, y también en lo que concierte a las artes, con la reproducción de obras pictóricas.

El abanico de temas desde los que se aborda la Primera Guerra Mundial en las revistas ilustradas se corresponde con el concepto global de este tipo de medio, que aspira a escribir de la forma más variada posible sobre todo aquello que puede resultar importante, interesante o actual para un público general. Valdría la pena consultar otras revistas de cada uno de estos dos países para realizar una comparación y estudiar cómo se llevó a la práctica este concepto en otras publicaciones periódicas de la época. 


\section{BIBLIOGRAFÍA}

A., Ch. (1917): «La marsellesa del Kronprinz», El Universal ilustrado, 10, s. p.

BoghaRdT, Thomas (2012): The Zimmermann Telegram: Intelligence, Diplomacy and America's Entry into World War I, Annapolis, Naval Institute Press.

BONA-FIDE (1917): «Por tierras de Europa. Una entrevista con el Marques de San Francisco», El Universal ilustrado, 31, s. p.

ESPRONCEDA, José de (1835): «Canción de pirata», El Artista, 5 de enero, pp. 43-44.

GonZÁleZ PEÑA, Carlos (1917): «Al margen de la semana», El Universal ilustrado, 1, s. p.

GuTIÉRREZ, Salvador E. (1915): «¿Por que existen algunos 'germanófilos' en México?», La Actualidad, 26, pp. 411-413.

IrachetA, Francisco de (1918): «Oración de Paz», Mundo Gráfico, 335, s. p.

LuGONES, Leopoldo (1918): «La Nueva civilización», El Universal ilustrado, 37, s. p.

MÉNDEZ MARTínez, Félix (1918): «Carta de la Guerra», Mundo Gráfico, 333, s. p.

MESA GuTIÉRREZ, José (1916): «El complejo conquistador alemán», en La Actualidad, 47, pp. 765-778.

Ministerio DE ESTADO (1914): «Sección de Política», Gaceta de Madrid, 7 de agosto, n. ${ }^{\circ}$ 219, p. 306.

PÉREZ DE AYALA, Ramón (1915): «Manifiesto de adhesion á las naciones aliadas», España. Semanario de la vida nacinal, 24, p. 6.

SCHWARZE, Ulrich (2013): Revisionskrieg und Gegenrevision: 1914-1939. Von den Schlachten des Ersten Weltkrieges bis zur Rückkehr des Memellandes, Tübingen, Hohenrain.

SORIANO, Manuel (1916): «iHaya Paz!», Mundo Gráfico, 229, s. p.

TAPIA, Luis de (1917): «La Nueva canción del pirata», La Actualidad, 58, p. 966.

WATSON GERARD, James (1918a): «Las revelaciones de un embajador», El Universal ilustrado, 39, s. p.

WATSON GERARD, James (1918b): «Hombres y cosas de Alemania», El Universal ilustrado, 41, s. p.

\section{ILUSTRACIONES}

Ilustración 1: «iEstoy completamente dispuesto a hacer la paz!», La Actualidad, 50, 30 de diciembre de 1916, p. 828

Ilustración 2: «Los directores alemanes de la gran batalla. Los directores aliados de la gran batalla», Mundo Gráfico, 342, 15 de mayo de 1918, s. p.

Ilustración 3: «Mujeres neoyorquinas substituyendo á los hombres en diversos oficios, por causa de la guerra», Mundo Gráfico, 326, 23 de enero de 1918, s. p.

Ilustración 4: Herrán, Saturnino: «Ilustraciones anacrónicas», El Universal ilustrado, 1, 11 de mayo de 1917, s. p.

Ilustración 5: «El emperador alemán..., en: El Universal ilustrado, 39, 1 de febrero de 1918, s. p. 
Ilustración 6: «Las pérdidas alemanas», El Universal ilustrado, 56, 31 de mayo de 1918, s. p.

Fecha de recepción: 5 de septiembre de 2019

Fecha de aceptación: 10 de septiembre de 2019

$$
9
$$

